Research article

\title{
Study of rhizospheric soil mycoflora of Cajanus cajan L. Millisp. in Halol taluka of Gujarat, India
}

\author{
Ravinayak Patlavath, Snehaben Ashokkumar Patel and Susy Albert* \\ Department of Botany, Faculty of Science, The Maharaja Sayajirao University of Baroda, Vadodara, India \\ *Corresponding Author: drsusyalbert@ rediffmail.com \\ [Accepted: 03 December 2019]
}

\begin{abstract}
The rhizospheric fungi are predominantly in close association with plants and essentially are important for plant well-being. Characterization of soil mycoflora for a crop will help in the improvement of agricultural techniques. In the present investigation six genus of fungi were isolated from the soil near root region of Cajanus cajan grown in agricultural fields of Halol taluka. In order to identify the fungi specific to the rhizospheric region a comparative study was conducted with the non-rhizospheric mycoflora. There was only $22 \%$ similarity in mycoflora between the two soil type which was predominantly due to the organic matter decomposers belonging to Aspergillus genera. The most common soil fungi identified were organic matter decomposers and a few phytopathogenic fungi such as Curvularia and Fusarium. The ShannonWiener diversity index obtained for the rhizospheric sample is 0.3 , indicating high fungal diversity in this soil. Overall, our study revealed that all the mycoflora identified from the C. cajan rhizospheric soil from agricultural field in Halol area is rich in fungal diversity and it is different from the non-rhizospheric soil.
\end{abstract}

Keywords: Pigeon pea - Fungal flora - Rhizosphere - Non-rhizosphere.

[Cite as: Patlavath R, Patel SA \& Albert S (2019) Study of rhizospheric soil mycoflora of Cajanus cajan L. Millisp. in Halol taluka of Gujarat, India. Tropical Plant Research 6(3): 462-466]

\section{INTRODUCTION}

Microorganisms are found in large numbers in soil predominantly consisting of bacteria and fungi. Fungi are one of the key components of the soil microflora. They are present either as mycelia, rhizomorphs or as spores. Mycoflora play a significant role in the decomposition of organic matter and indirectly contribute to soil fertility. Rhizosphere can be defined as a narrow region of the soil that is directly influenced by roots. This region has a very diverse mycoflora which is determined by the type of the plant and its interaction with the microbes. The rhizospheric fungi are involved in numerous biological process like biodegradation, mineralization, symbiotic and non-symbiotic association with plant which improves soil fertility, protects from plant pathogen and enhances plant growth (Kennedy \& Smith 1995). A few rhizospheric fungi are in very close association with the root tissues in the form of mycorrhiza where the fungal hyphae grows within the root tissue and around the root system (Phillips \& Hayman 1970). This association not only promotes the plant growth but also protects plant from dehydration. Thus, understanding the rhizospheric microflora is significant for conservation of the micro-environment in soil ecosystem for crop improvement. The plant rhizosphere system, in turn, affects biomass and activity of soil microorganism that is generally enhanced due to root exudates. The rhizospheric mycoflora of a plant will vary with the nature of soil and climatic condition (Deshmukh et al. 2016). As the root exudates change plant life cycle, interestingly the composition of rhizospheric mycoflora also varies during different developmental stages of the plant (Houlden et al. 2008, Deshmukh et al. 2016). Therefore, the rhizospheric mycoflora is unique for a plant which is dependent on the property of soil, root exudate and interaction with microbes. Most of the reported studies have focused only on bacterial communities in the rhizosphere.The present research is focused to study the fungal diversity of the rhizospheric region of Cajanus cajan. crop plant in agricultural field. Pigeon pea is the sixth important legume crop of the world and it is one of the major crops of Gujarat state in India. Pigeon pea is cultivated in 2.65 lakh hectare area of Gujarat leading to production of 2.94 lakh ton of the pulse annually (http://agropedia.iitk.ac.in). A comparison of the 
mycoflora of the rhizospheric soil and non-rhizospheric soil has been analyzed in order to identify the fungi specific to C. cajan in Halol region of Gujarat.

\section{MATERIAL AND METHODS}

Study area and soil sample collection

Rhizosphere and Non-Rhizosphere soil samples of Pigeon Pea [Cajanus cajan (L.) Millsp.] were collected from Arad village of Halol taluka, Panchmahal district, Gujarat state. It is located at $22.5072^{\circ} \mathrm{N}$ and $73.4718^{\circ} \mathrm{E}$. Soil samples were collected in the month of September during rainy season. The rhizospheric soil and nonrhizospheric soil collection was done on the same day. The temperature of the region ranges from $28^{\circ} \mathrm{C}$ to $35^{\circ} \mathrm{C}$ during the rainy season. The annual rainfall recorded for this region is $200 \mathrm{~mm}$ to $330 \mathrm{~mm}$. The soil type in this region is red and black type. The other major crops grown in the region are paddy, wheat, maize, groundnut and cotton which are cultivated in Rabi/kharif season. Soil samples were collected from 3 to 4 -inch depth from the surface layer for nonrhizospheric soil.

\section{Isolation of mycoflora from soil}

The rhizospheric and the non-rhizospheric mycoflora was isolated by plating the soil suspensions on sterile Potato Dextrose Agar (PDA; pH 5.5) plates. For this, $1 \mathrm{gm}$ of the soil sample was suspended in $10 \mathrm{ml}$ of sterile double distilled water and this was serially diluted further $\left(10^{-1}\right.$ to $\left.10^{-6}\right)$. For plating, $0.1 \mathrm{ml}$ of each dilution was spread on PDA supplemented with $1 \%$ streptomycin to inhibit bacterial growth. Plates of all dilutions were were incubated at room temperature $\left(28 \pm 2^{\circ} \mathrm{C}\right)$ for seven days. The experiment was repeated twice with the same soil sample.

\section{Staining and identification of fungi}

Identification of the isolated fungi was performed by studying the colony morphology and the sporulation pattern which was examined microscopically. For this, the plates were incubated for longer period till the sporulation was visible. A small portion of the fungal colony was aseptically transferred on a glass slide using sterile forceps and stained with lactophenol/ cotton blue stain and observed under 40X objective of compound microscope. Photographs were taken with the help of Am-scope camera. The fungal species were identified with the help of Prof. Arun Arya from department of botany, The M S University of Baroda, India.

\section{Data analysis}

The similarity between the mycoflora of the rhizospheric and non-rhizospheric soil was compared using Sorensen index of similarity (IS) (Wolda 1981) using the formula given below:

$$
\text { IS }=\frac{2 \mathrm{C}}{\mathrm{A}+\mathrm{B}} \times 100
$$

Where, $\mathrm{A}=$ the total number of species found in soil sample A (Rhizosphere soil); $\mathrm{B}=$ the total number of species found in soil sample B (Non-rhizosphere); $\mathrm{C}=$ the number of species common in both the samples.

Further, the fungal diversity of the rhizospheric soil sample was evaluated by the Shannon-Wiener index $\left(\mathrm{H}^{\prime}\right)$ (Spellerberg \& Fedor 2003) and calculated according to the formula:

$$
H^{\prime}=-\sum_{i=1}^{n} p_{i} \operatorname{In} p_{i}
$$

Where, $p i$ is the proportion of number of colonies of the $i$-th species to the total number of colonies when $i=$ $1,2,3, \ldots, n ; E_{H}=H^{\prime}-\mathrm{N}$ where $\mathrm{N}=$ total number of species.

For all data analysis MS-excel software was used.

\section{RESULTS AND DISCUSSION}

Fungal diversity in the rhizospheric and the non-rhizospheric soil

A comparative analysis of the rhizospheric and the non-rhizospheric soil sample was performed in order to identify the C. cajan rhizosphere specific fungi in the Halol area of Guajrat, India. For this, the rhizospheric and non rhizospheric soil samples were collected in the month of September during rainy season assuming the soil will be enriched with fungi after the first rain in the month June. A uniform soil suspension of both the samples were spread on fungal selective media, PDA (pH 5.5) (Fig. 1). The bacterial growth was inhibited by antibiotics, streptomycin incorporated in the medium. Microscopic analysis of fungi isolated from both the soil samples revealed presence of 6 different fungal species in the $C$. cajan rhizospheric soil and 3 fungal species in the nonrhizospheric soil sample (Figs. $2 \& 3$ ). Mixed cultures were further subcultured to obtain pure culture of the 

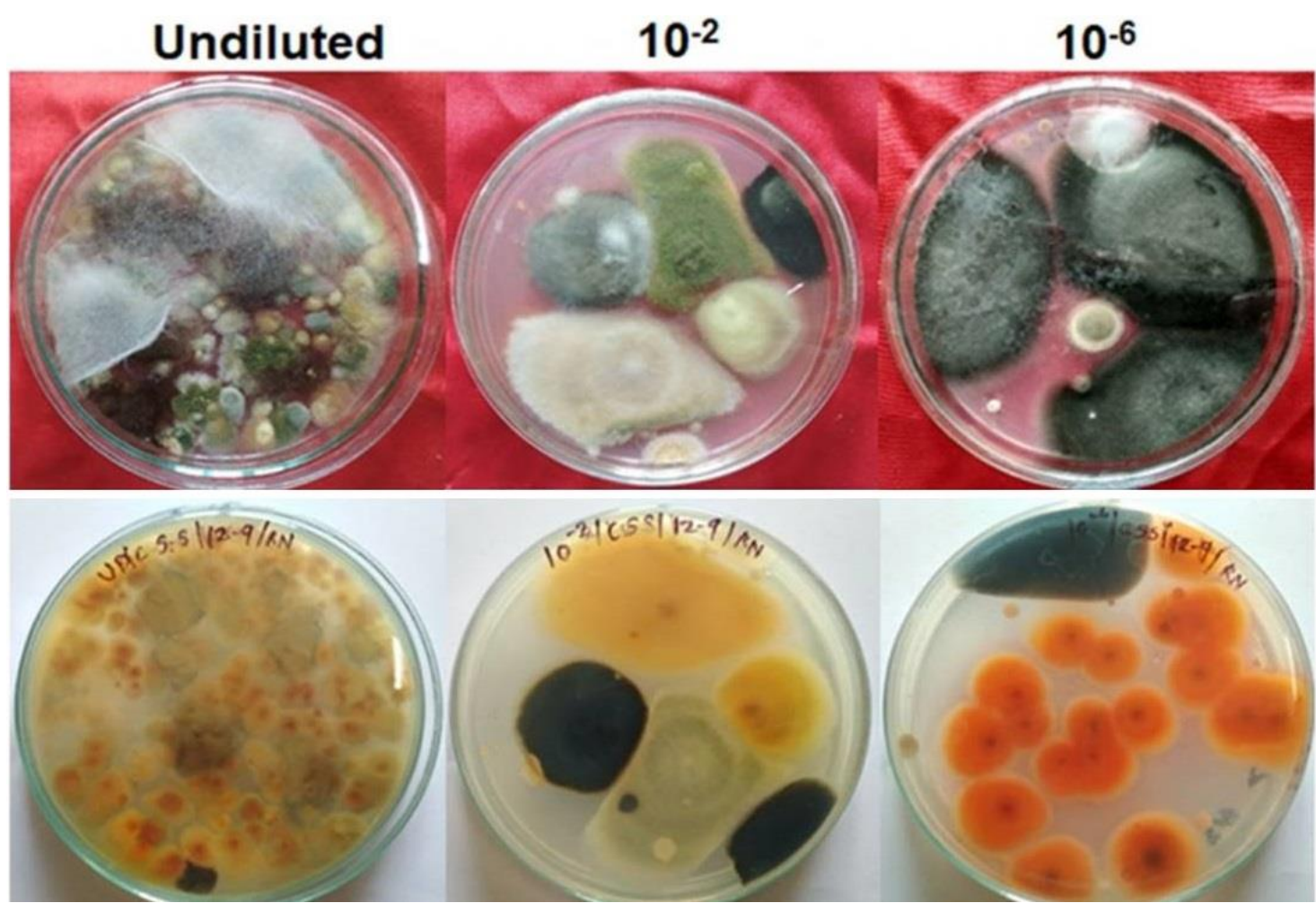

Figure 1. Fungal colonies grown on PDA plates after seven days of incubation.
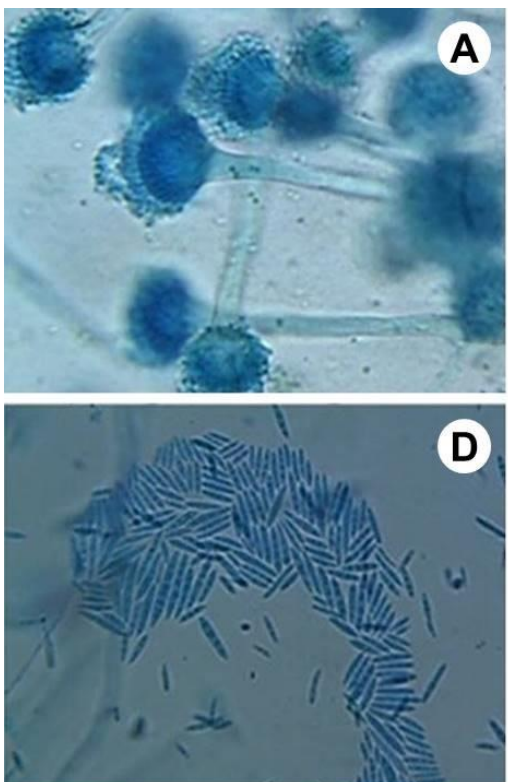
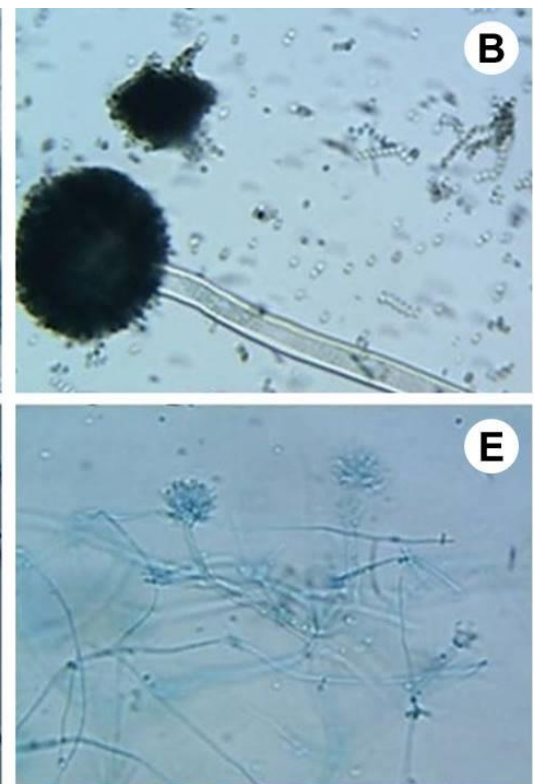
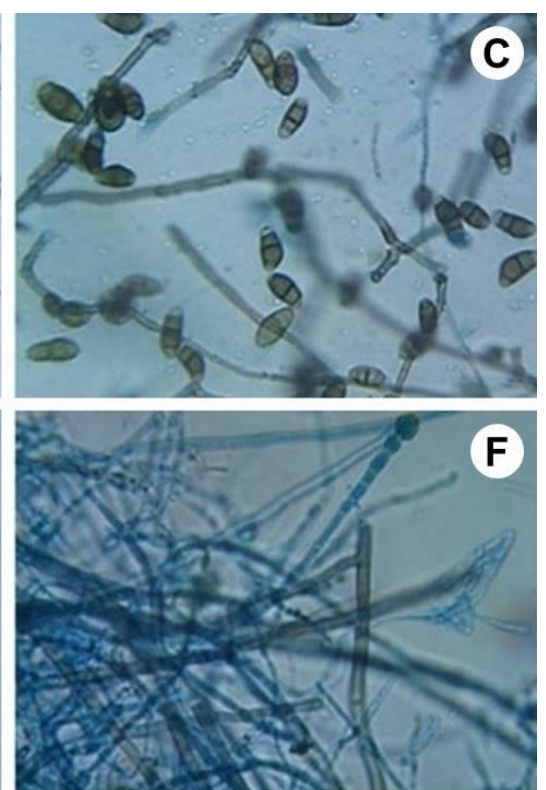

F

Figure 2. Fungal species identified in the rhizospheric soil sample: A, Aspergillus flavus Link; $\mathbf{B}$, Aspergillus niger van Tieghem; C, Curvularia sp.; D, Fusarium sp.; E, Syncephalastrum sp.; F, Unidentified fungi-2.
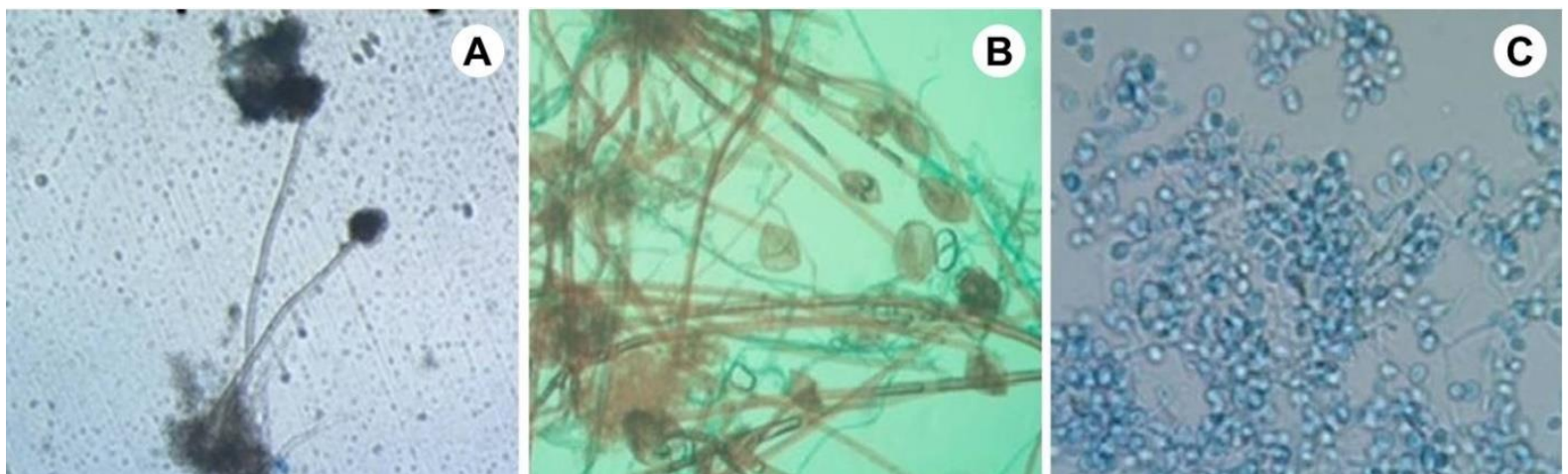

Figure 3. Fungal species identified in the non-rhizospheric soil sample: A, Aspergillus niger van Tieghem; B, Rhizopus stolonifer Vuillemin; C, Unidentified fungi-1. 
fungal isolates. The fungal species were identified on the basis of colony characteristics and sporulation pattern. The different species identified as common in the two experimental replicates belonged to the genera Aspergillus, Rhizopus, Fusarium, Curvularia and Syncephalastrum (Figs. $2 \&$ 3). One of the species isolated from the non-rhizospheric soil remained unidentified but it appears to have yeast-like cellular structures. The majority of the fungal species belonged to the Ascomycota family. The details of each fungal species are given in table 1. The most common soil fungi identified were organic matter decomposers like Rhizopus and Aspergillus. The decomposers like Aspergillus sp., were common to both the rhizospheric and the nonrhizospheric soil. Rhizopus was found only in the non-rhizospheric soil. However, Jalander \& Gachande (2011) reported that Rhizopus sp. are also found to be associated with a few varieties of $C$. cajan grown in Telangana state of India. There were also many phytopathogenic fungi such as Curvularia and Fusarium. Out of these two plant pathogens, Fusarium remains dormant the soiland when the C. cajan crop is grown in the next season, the pathogen revives and causes serious necrotrophic wilt disease in this crop (Gordon 2017). The present study indicates that the rhizospheric soil of $C$. cajan from Halol is enriched with decomposer fungi and $C$. cajan specific fungal pathogen.

Table 1. Different species identified in rhizospheric and non-rhizospheric soil of Cajanus cajan L. Millisp. in Halol region of Gujarat.

\begin{tabular}{|c|c|c|c|}
\hline Fungal species identified & Rhizopshere & Non-Rhizosphere & Family \\
\hline $\begin{array}{l}\text { Aspergillus niger van } \\
\text { Tieghem }\end{array}$ & + & + & Trichocomaceae \\
\hline $\begin{array}{l}\text { Rhizopus stolonifer } \\
\text { Vuillemin }\end{array}$ & - & + & Mucoraceae \\
\hline Aspergillus flavus Link & + & - & Trichocomaceae \\
\hline Curvularia sp. & + & - & Pleosporaceae \\
\hline Fusarium sp. & + & - & Nectriaceae \\
\hline Syncephalastrum & + & - & Syncephalastraceae \\
\hline Unidentified fungi-1 & - & + & \\
\hline Unidentified fungi-2 & + & - & \\
\hline
\end{tabular}

Note: Symbol '+' and '-' indicates presence or absence of particular species respectively.

Similarity index rhizospheric and nonrhizospheric soil mycoflora

In order to calculate the similarities of the fungal communities between the two soil types, we used Sorensen's index of similarity for comparison (Wolda 1981). If Sorensen's index is higher than 55\% it indicates the soil samples have similar fungal communities and a value lower than $35 \%$ indicates a low similarity between the samples under study (Puangsombat et al. 2010). In our experiment, we have obtained Sorensen's index as low as $22.2 \%$, which indicated that there are more differences in the fungal community than similarity (Table 2). Plant exudates secreted around the root system is one of the key factors that select the microbial pattern in the rhizospheric region (Deshmukh et al. 2016). The non-rhizospheric soil lacks the root exudates thus the composition is mainly dependent on the soil's physical and chemical properties. The similarity between the two soil typewas contributed by the decomposers of Aspergillus sp. which was common to both the soil samples and the dissimilarities were due to the phytopathogen and other saprophytic fungi present only in the rhizospheric soil.

Table 2. Diversity and abundance of fungal species in rhizospheric and non-rhizospheric soil of Cajanus cajan L. Millisp. in Halol region of Gujarat.

\begin{tabular}{lrrr}
\hline & $\begin{array}{r}\text { Rhizosphere } \\
(\mathbf{A})\end{array}$ & $\begin{array}{r}\text { Non-rhizosphere } \\
(\mathbf{B})\end{array}$ & $\begin{array}{r}\text { Common in } \\
(\mathbf{A} \text { \& B = C) }\end{array}$ \\
\hline $\begin{array}{l}\text { Number of species } \\
\begin{array}{l}\text { Sorensen index of } \\
\text { similarity (IS) }\end{array}\end{array}$ & 6 & 3 & 1 \\
\hline
\end{tabular}

Diversity index for rhizospheric mycoflora

We have calculated the diversity index $(\mathrm{H})$ for only rhizospheric soil as the number of species obtained is more than the non-rhizospheric soil. The Shannon-Wiener diversity index $\left(\mathrm{H}^{\prime}\right)$ is used to calculate the diversity of any ecosystem (Spellerberg \& Fedor 2003). A lower $E_{H}$ value indicates more diversity while higher $E_{H}$ value indicate less diversity. The $\mathrm{E}_{\mathrm{H}}$ value obtained is 0.3 which is closer to zero indicating high fungal diversity in the C. cajan rhizospheric soil.

\section{CONCLUSIONS}

Overall our study revealed that all the mycoflora of the $C$. cajan rhizospheric soil from agricultural field in 
Halol area is rich in fungal diversity and the predominant species were either decomposers like Aspergillus sp. or $C$. cajan phytopathogens. Unlike Jalander \& Gachande (2011), we didn't find many species of fungi in $C$. cajan rhizosphere namely, Penicillium sp., Trichoderma sp. Rhizopus sp. etc. This may be due to the variation in soil composition and the climatic conditions of Halol which is very different from Telangana state of India. We have reported presence of Syncephalastrum in the $C$. cajan rhizospheric soil which was not reported before. The present study is in conjuncture with previously reported studies that the rhizospheric soil has more fungal diversity than the non-rhizospheric soil. The root exudates released by $C$. cajan root might be responsible for the dissimilarities between rhizospheric and nonrhizospheric mycoflora. Thus, our observations add new information to the scientific data available on C. cajan rhizospheric mycoflora.

\section{ACKNOWLEDGEMENTS}

We acknowledge Prof. Arun Arya for his guidance throughout the work. Present research was funded by the start-up grant given to Ravinayak Patlavath by Research Consultancy Cell, The M S University of Baroda, Vadodara, India.

\section{REFERENCES}

Deshmukh P \& Shinde S (2016) Beneficial role of rhizosphere mycoflora in the field of agriculture: An overview. International Journal of Science and Research 5(8): 529-533.

Gordon TR (2017) Fusarium oxysporum and the Fusarium wilt syndrome. Annual Review of Phytopathology 55: 23-39.

Houlden A, Timms-Wilson TM, Day MJ \& Bailey MJ (2008) Influence of plant developmental stage on microbial community structure and activity in the rhizosphere of three field crops. FEMS Microbiology Ecology 65(2): 193-201.

Jalander V \& Gachande BD (2011) Rhizosphere and non-rhizosphere mycoflora of different varieties of pigeon pea (Cajanus cajan (L.) Millsp.) Geobios 38(1): 37-40.

Kennedy AC \& Smith KL (1995) Soil microbial diversity and the sustainability of agricultural soils. Plant and Soil 170(1): 75-86.

Phillips JM \& Hayman DS (1970) Improved procedures for clearing roots and staining parasitic and vesiculararbuscular mycorrhizal fungi for rapid assessment of infection. Transactions of the British mycological Society 55(1): 158-IN18.

Puangsombat P, Sangwanit U \& Marod D (2010) Diversity of soil fungi in different land use types in the KumHuai Raeng Forest Reserve, Trat Province. Journal of Agricultural Science Science 44: 1162-1175.

Spellerberg IF \& Fedor PJ (2003) A tribute to Claude Shannon (1916-2001) and a plea for more rigorous use of species richness, species diversity and the 'Shannon-Wiener Index. Global Ecology and Biogeography 12(3): 177-179.

Wolda H (1981) Similarity indices, sample size and diversity. Oecologia 50(3): 296-302. 